\title{
MONITORAMENTO DA CONCENTRAÇÃO DE COMPOSTOS NITROGENADOS NA QUALIDADE DA ÁGUA NAS BACIAS DO PARANAPANEMA III E IV
}

\author{
Cássia Maria Bonifácio ${ }^{1}$ \\ Osvaldo Tarelho Junior ${ }^{2}$ \\ Célia Regina Granhen Tavares ${ }^{3}$
}

RESUMO: Este trabalho teve por objetivo o monitoramento dos parâmetros de temperatura, $\mathrm{pH}$, nitrogênio amoniacal, nitrito e nitrato nas águas das bacias hidrográficas do rio Paranapanema 3 e 4, no estado do Paraná. Para este fim, foram coletadas amostras em seis pontos, no período de fevereiro a julho de 2013. Os resultados obtidos mostraram trechos críticos de poluição hídrica do tipo difusa, devido ao uso do solo misto - urbano e agrícola, que, em tempos de evento de precipitação, os materiais são transportados aos corpos d'água, alterando a qualidade da água.

Palavras-Chave: Bacia hidrográfica. Poluição hídrica. Rio Paranapanema 3 e 4.

\section{Introdução}

Com desmatamento desenfreado, consequência do uso e ocupação do solo, tem se registrado gradativas alterações referentes à qualidade da água dos corpos hídricos. As modificações geradas na superfície do solo altera a rugosidade deste, levando a aumento ou redução do escoamento superficial em eventos pluviométricos, ou seja, maiores cargas de constituintes podem alcançar os rios (SCHNEIDER et al, 2011). Levando em consideração que o ciclo hidrológico natural é constituído por diferentes processos físicos,

\footnotetext{
${ }^{1}$ Geógrafa, Mestre em Geografia, Pesquisadora Bolsista CNPQ/FINEP. Universidade Estadual de Maringá. Email: kaoruyuri@hotmail.com

${ }^{2}$ Engenheiro Químico, Mestrando em Engenharia Química, Bolsista CAPES. Universidade Estadual de Maringá. Email: osvaldotarelhojr@hotmail.com

${ }^{3}$ Prof. Dra. do Departamento de Engenharia Química. Universidade Estadual de Maringá.
} 
químicos e biológicos, é importante lembrar que as atividades realizadas dentro da bacia hidrográfica serão refletidas no corpo hídrico.

Vale ressaltar a importância do desenvolvimento de pesquisas voltadas ao monitoramento e diagnóstico ambiental, visando fortalecer as bases científicas na área, permitindo a permutação de medidas mitigadoras de controle e manejo das fontes poluidoras (OLIVEIRA, et al, 2009).

Este trabalho apresenta, portanto, o objetivo de avaliar a influência de alguns parâmetros físico-químicos, na qualidade da água das bacias do rio Paranapanema 3 e 4, norte do Paraná, por meio do monitoramento dos seguintes parâmetros: temperatura, $\mathrm{pH}$, nitrogênio amoniacal, nitrito e nitrato, referentes aos meses de fevereiro a julho de 2013.

\section{Caracterização da área de estudo}

Bacia do Paranapanema III

A Bacia do Paranapanema 3 é formada pela área de drenagem de 12 tributários que deságuam no rio Paranapanema entre a foz do rio Tibagi, próximo ao lago da Usina Hidrelétrica de Capivara, e a foz do rio Pirapó. Possui uma área total de $3.564,30 \mathrm{~km}^{2}$, cerca de $2 \%$ da área do Estado, compreendendo 19 municípios e uma população de 110.516 habitantes, sendo 84.583 na zona urbana (IBGE - 2004). 


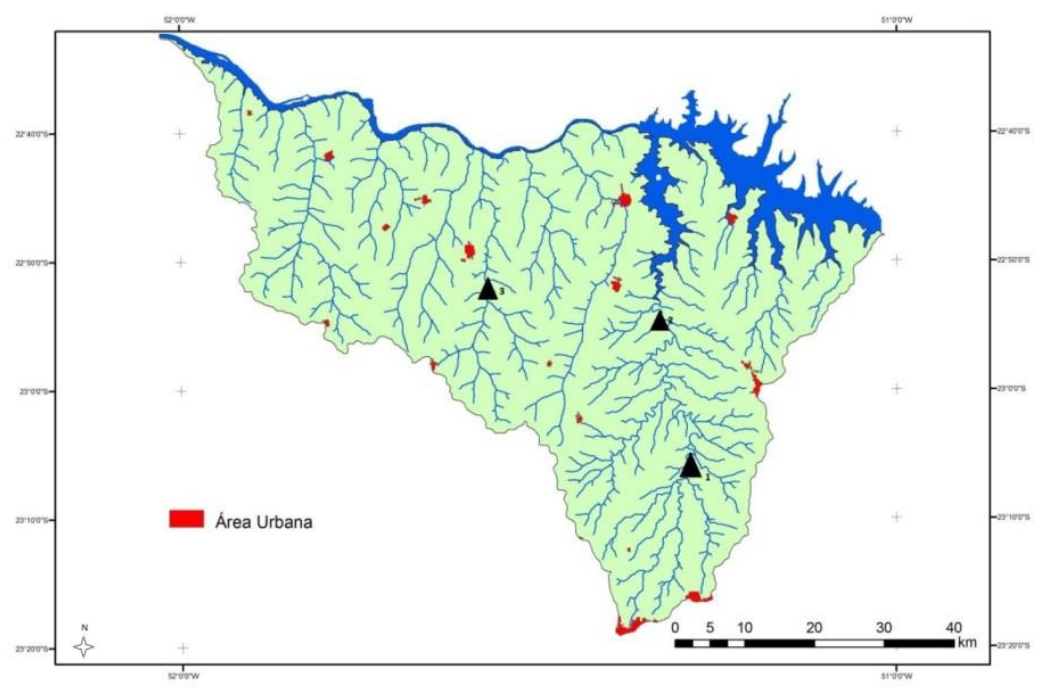

Figura 01- Bacia do rio Paranapanema 3, com os pontos de coleta.

\section{Bacia do Paranapanema IV}

A Bacia do Paranapanema 4 localiza-se a oeste do rio Pirapó, contando com 15 afluentes do rio Paranapanema até a foz do Ribeirão do Tigre. Possui uma área total de $4.139 \mathrm{~km}^{2}$ ( $2 \%$ da área do Estado), abrangendo 18 municípios e uma população total de 80.808 habitantes, sendo 58.692 vivendo na zona urbana (IBGE - 2004).

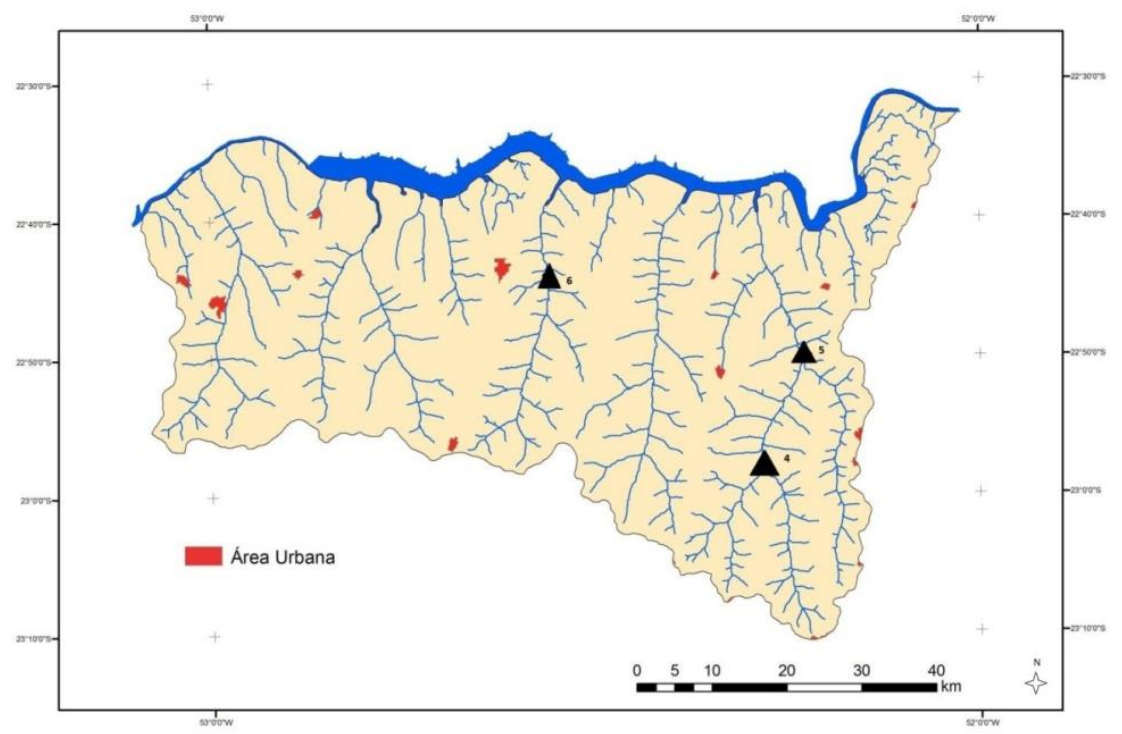


Figura 02 - Bacia do Paranapanema 4, com os pontos de coleta.

\section{Materiais e métodos}

Os pontos de coleta (Figura 1 e 2) foram definidos a partir das características pedológicas e geomorfológicas de cada região, e nas atividades predominantes da bacia. Optou-se por locais em que o acesso fosse favorável com a presença de ponte sob o curso d'água. Foram definidos três pontos de coleta em cada bacia, que podem ser visualizados no Quadro 1.

Quadro 1 - Descrição dos pontos de coleta.

\begin{tabular}{|c|c|c|c|}
\hline PONTO & Bacia & Curso d'água & Município \\
\hline 1 & \multirow{4}{*}{ Paranapanema III } & Ribeirão Vermelho & Cambé \\
\cline { 3 - 4 } & & Ribeirão Vermelho & $\begin{array}{c}\text { Divisa entre } \\
\text { Florestópolis e Alvorada } \\
\text { do Sul }\end{array}$ \\
\hline 3 & & Ribeirão Caneleiro & Centenário do Sul \\
\hline 4 & \multirow{4}{*}{ Paranapanema IV } & Ribeirão Francisco & $\begin{array}{c}\text { Divisa entre Cruzeiro do } \\
\text { Sul e Alto Paraná }\end{array}$ \\
\cline { 4 - 4 } & & Ribeirão Francisco & $\begin{array}{c}\text { Divisa entre São João } \\
\text { do Caiuá e Paranacity }\end{array}$ \\
\cline { 4 - 5 } & & Rio da Coroa do Frade & $\begin{array}{c}\text { Divisa entre Terra Rica } \\
\text { e Paranavaí }\end{array}$ \\
\hline 6
\end{tabular}

Fonte: Elaborado pelo autor.

As amostras eram coletadas in loco, por meio de corda e balde, e transportadas em caixas térmicas, com capacidade para acondicionar frascos de plástico opacos de volumes diversos, no interior dos quais as amostras eram preservadas inicialmente com gelo e, posteriormente, estocadas em freezer.

Dentre os parâmetros medidos in loco estão a temperatura da água e o pH, que eram obtidos com o auxílio de sonda marca Hach.

Já os ensaios laboratoriais eram realizados no Laboratório de Gestão, Preservação e Controle Ambiental do Departamento de Engenharia Química da Universidade Estadual de Maringá.

O parâmetro de nitrogênio amoniacal $\left(\mathrm{N}^{\left.-\mathrm{NH}_{3}\right)}\right.$ foi determinado por meio do método Nessler. 
Já para os parâmetros de nitrito $\left(\mathrm{NO}_{2}^{-}-\mathrm{mg} \mathrm{L}^{-1}\right)$, e nitrato $\left(\mathrm{NO}_{3}^{-}-\mathrm{mg} \mathrm{L}^{-1}\right)$ utilizaram-se o Diazotization Method e o Cadmium Reduction Method, respectivamente. Tais metodologias estão descritas no equipamento Portable Datalogging Spectrophotometer HACH DR/2010, conforme recomendações da APHA (1995).

\section{Resultados}

Os dados obtidos em campo e nas análises laboratoriais estão apresentados nas Figuras 3 a 8. Conforme a Portaria SUREHMA oo 004 de 21/03/1991, os cursos de água contidos nas bacias do rio Paranapanema 3 e 4 pertencem à classe 2 (PARANÁ, 1991).

Os resultados apresentados serão discutidos com base nos padrões de enquadramento de cursos d'água estabelecidos na Resolução CONAMA no 357/2005 (BRASIL, 2005).

Na Figura 3, a seguir, é possível observar a variação de temperatura da água. A temperatura mínima registrada foi de $17,4^{\circ} \mathrm{C}$, no ponto 4 , mês de maio, e a máxima de $31,9^{\circ} \mathrm{C}$, no ponto 6 , referente ao mês de abril.

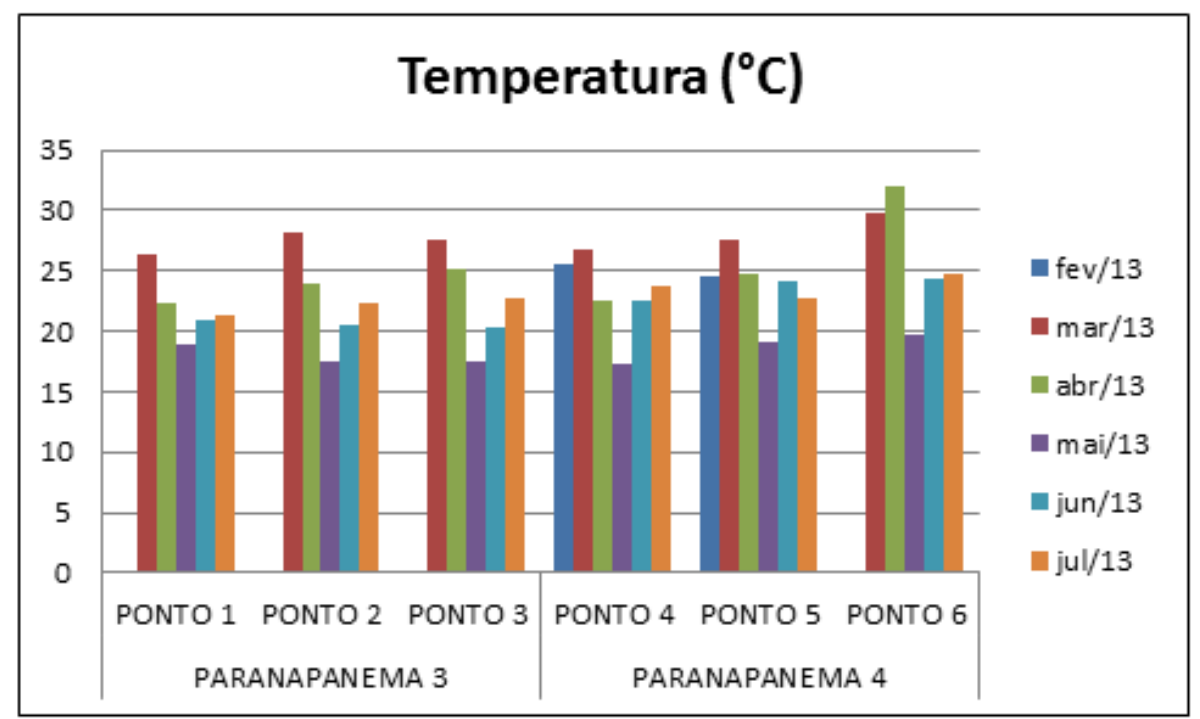

Figura 3 - Temperatura $\left({ }^{\circ} \mathrm{C}\right)$ das bacias do rio Paranapanema 3 e 4.

Para o parâmetro de $\mathrm{pH}$ (Figura 4), os valores variaram de 5,84, para o ponto 6, no mês de abril, e 7,58, para o ponto 1, no mês de abril. A Resolução 357 do CONAMA, 
define que o $\mathrm{pH}$ para rios de classe 2, deve variar de 6 a 9. Todavia, os pontos 4 e 6 apresentaram valores abaixo do estipulado. Tais valores de $\mathrm{pH}$ podem estar relacionados tanto à poluição hídrica, como a quantidade do carbonato de cálcio, presente nos solos da região.

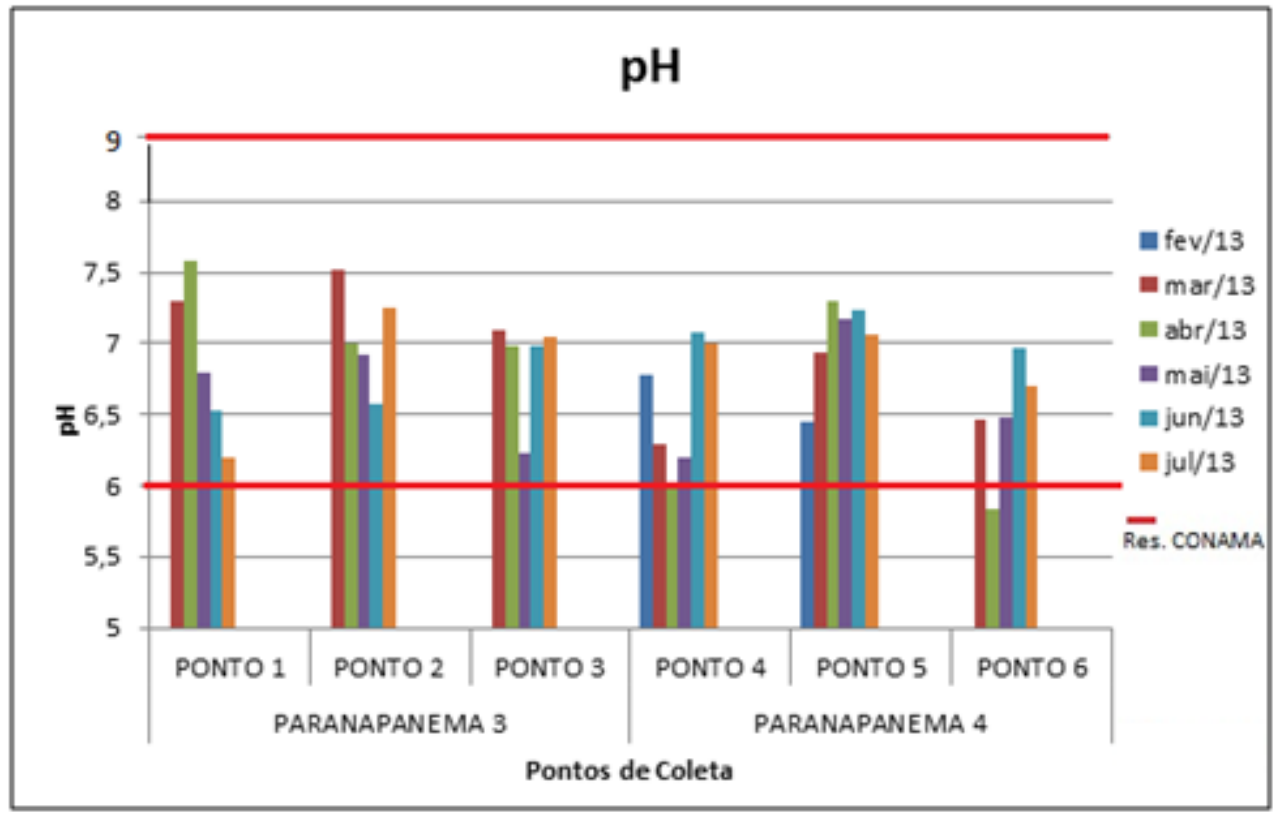

Figura 4 - Valores de $\mathrm{pH}$ para as bacias do rio Paranapanema 3 e 4.

Os resultados do parâmetro Nitrogênio Amoniacal (Figura 5) estão dentro do estabelecido pela legislação, que é de $2,18 \mathrm{mg} / \mathrm{L}$ para ambientes lóticos. Todavia, é importante observar que, mesmo com valores aceitáveis, o ponto 6 apresentou os maiores resultados, na maior parte dos meses, se comparado aos demais pontos de coleta. 


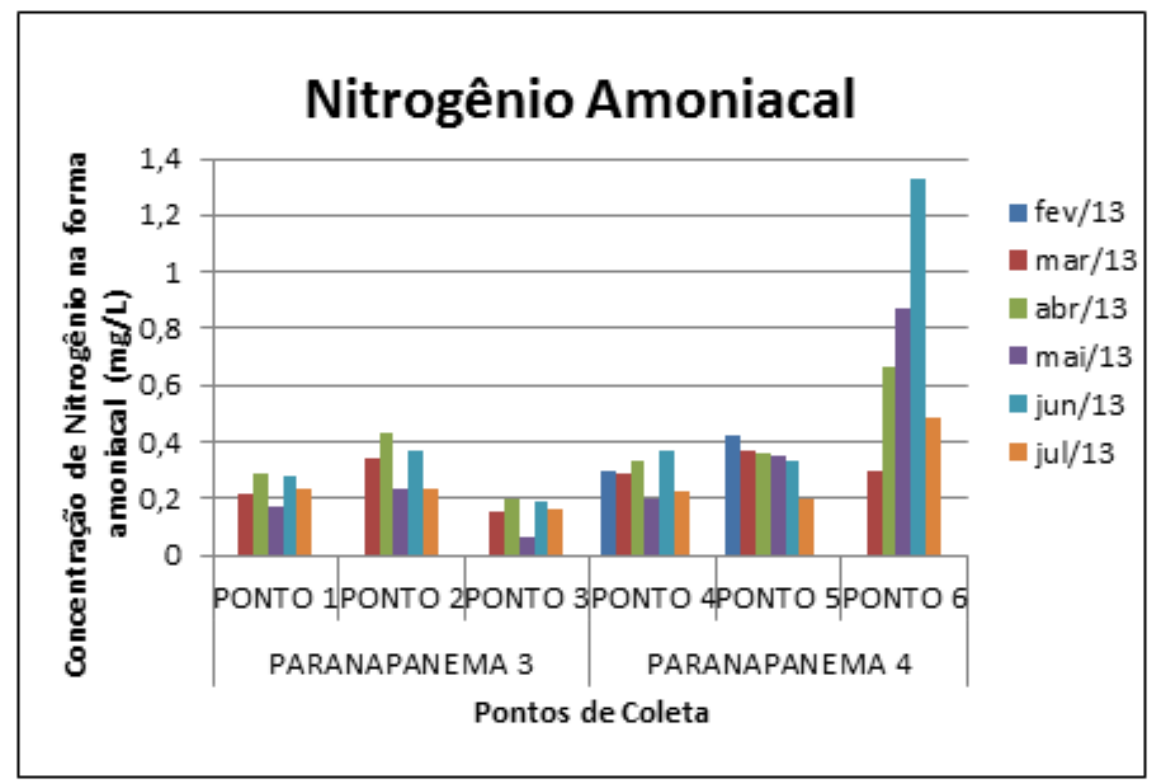

Figura 5 - Variação do Nitrogênio Amoniacal das bacias do rio Paranapanema 3 e 4.

Já referente ao parâmetro Nitrito (Figura 6), durante o período de coleta foram observados valores superiores, em todos os pontos e na maior parte dos meses, ao estabelecido na legislação $\left(1,0 \mathrm{mg} \mathrm{L}^{-1}\right)$. Novamente, o ponto 6 aparece com os valores mais elevados.

As concentrações desse parâmetro podem se tornar elevadas, devido ao uso intensivo de fertilizantes na agricultura, e no lançamento de efluentes (ROSSI et al.,2007).

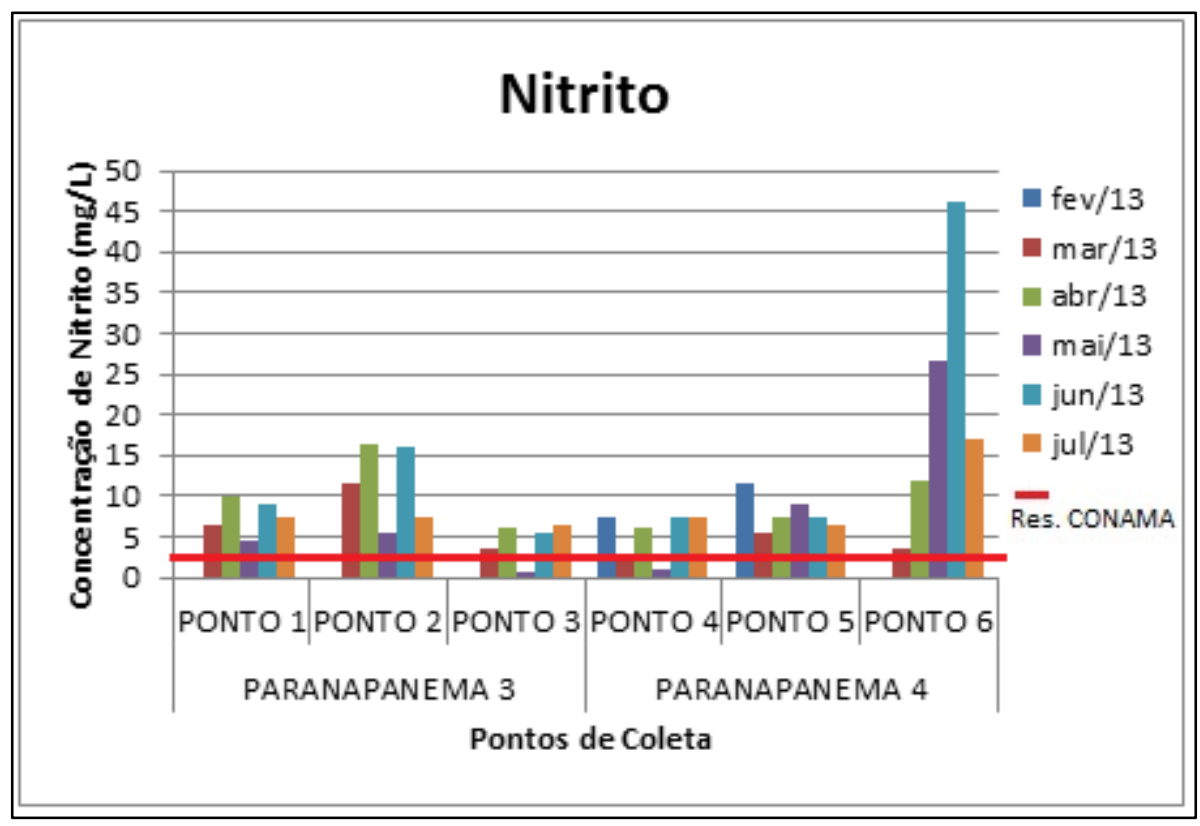


Figura 6 - Variação da concentração de Nitrito $\left(\mathrm{mg} \mathrm{L}^{-1}\right)$ para as bacias do rio Paranapanema 3 e 4.

Em relação à concentração de nitrato (Figura 7), em vários meses de coleta, as concentrações estiveram acima daquela permitida pela legislação $\left(10,0 \mathrm{mg} \mathrm{L}^{-1}\right)$. Somente o ponto 3, pertencente a bacia do Paranapanema 3, apresentou, em todos os meses, valores aceitáveis. Contudo, em relação ao ponto 6 , os valores foram demasiadamente extrapolados.

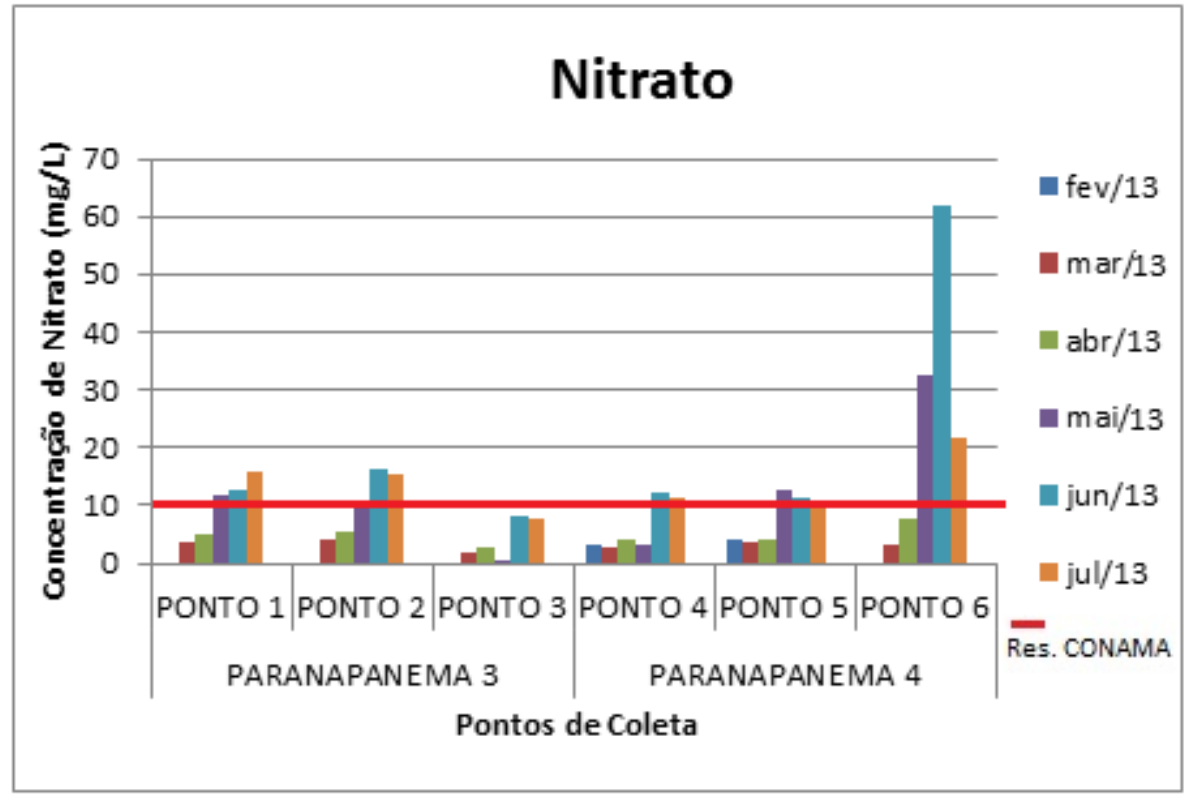

Figura 7 - Variação da concentração de nitrato $\left(\mathrm{mg} \mathrm{L}^{-1}\right)$ para as bacias do rio Paranapanema 3 e 4.

\section{Considerações finais}

Ao analisar os resultados obtidos para os parâmetros de temperatura, pH, nitrogênio amoniacal, nitrito e nitrato referentes aos meses de fevereiro a julho de 2013 nas bacias do rio Paranapanema 3 e 4, foi possível verificar que o trecho mais crítico de poluição hídrica foi o ponto 6, localizado em uma área de uso de ocupação mista - agrícola e urbana, apresentando poluição difusa, devido à área de ocorrência. Sendo assim, é importante destacar a influência do escoamento superficial do solo em eventos de precipitação sobre a qualidade da água. 


\section{Agradecimentos}

Os autores agradecem ao CNPQ, CAPES e FINEP pelo auxílio financeiro.

\section{Referências}

APHA, American Public Health Association. Standard Methods for the Examination for Water and Wastewater. $14^{\text {th }}$ ed. Washington D.C.1995.

BRASIL. MINISTÉRIO DO MEIO AMBIENTE CONSELHO NACIONAL DO MEIO AMBIENTE. Resolução no. 357, de 17 de março de 2005. Dispõe sobre a classificação dos corpos de água e diretrizes ambientais para o seu enquadramento, bem como estabelece as condições e padrões de lançamento de efluentes, e dá outras providências. Brasília, 2005.

FREIRE, R.; BONIFÁCIO, C. M.; FREITAS, F. H.; SCHNEIDER, R. M.; TAVARES, C. R. G.; Nitrogen forms and total phosphorus in water courses: a study at Maringá streamParaná state. Acta Scientiarum, v. 35i4. 2011.

OLIVEIRA, T. M. B. F.; SOUZA, L. D. S.; CASTRO, S. S. L. Dinâmica da série nitrogenada nas águas da bacia hidrográfica Apodi/Mossoró - RN - Brasil. Eclética Química, v. 34, n. 3, 2009.

ROSSI, P.; MIRANDA, J.H.; DUARTE, S.N. Curvas de distribuição de efluentes do íon nitrato em amostras de solo deformadas e indeformadas. Escola Superior de Agricultura "Luiz de Queiroz" ESALQ/USP, Piracicaba. 2007. 